\title{
A contribuição dos meios públicos e alternativos para a democracia participativa
}

Juan Díaz Bordenave

Doutor em Comunicação pela Universidade do Estado de Michigan, mestre em Jornalismo Agrícola pela Universidade de Wisconsin (EUA). Atualmente membro do Conselho Nacional e de Educação e Cultura do Paraguai.

E-mail: diazbordenave@gmail.com

Resumo: $\mathrm{O}$ artigo pretende demonstrar que a Comunicação Pública e a Comunicação Comunitária são instrumentos essenciais da democracia participativa, aqui conceituada como cogoverno do Estado com a sociedade civil organizada. No Brasil, o conceito foi aplicado através do orçamento participativo, pela prefeitura petista de Porto Alegre (RS).

Palavras-chave: Democracia participativa, funções estatais da sociedade civil, radiodifusão.
Abstract: This article argues that the Public and Communitarian Communication are key instruments of participatory democracy, here defined as joint management of the state together with organized civil society. In Brazil, the concept was applied through the Participartory Budgeting, by the Workers Party government of Porto Alegre City (RS).

Keywords: Participatory democracy, government functions of civil society, broadcasting, communication, education.

A convite do Núcleo Ciudadano para el Cambio [Núcleo Cidadão para a Mudança], do qual sou membro no Paraguai, o professor brasileiro Ivandro da Costa Sales, autor do livro Os desafios da gestão democrática da sociedade $e^{1}$, proferiu duas conferências em Assunção sobre a experiência brasileira com a democracia participativa ${ }^{2}$.

Ivandro nos ajudou a entender melhor a diferença que há entre a democracia representativa e a participativa, tema bastante atual no Paraguai, e que tem provocado reações adversas de vários políticos eminentes que pensam que a democracia participativa é uma ameaça à representativa. Para eles foi uma surpresa constatar que na Constituição Nacional afirma-se que nossa democracia é republicana, representativa, participativa e pluralista. Acreditam que a democracia participativa consiste em acabar com o Parlamento e substituí-lo por referendos e assembleias populares, quando não por uma imaginária ditadura do proletariado.

Recebido: 14.06.2010

Aprovado: 23.11 .2010

1. SALES, Ivandro da Costa. Os desafios da gestão democrática da sociedade. Recife: Editora UFPE, 2008.

2. Pronunciamiento realizado durante o II Foro Nacional de La Comunicación, promovido pela Secretaría de Información y Comunicación para el Desarrollo de la Presidencia de la República del Paraguay (Sicom), nos dias 15 e 16 de abril de 2010. 


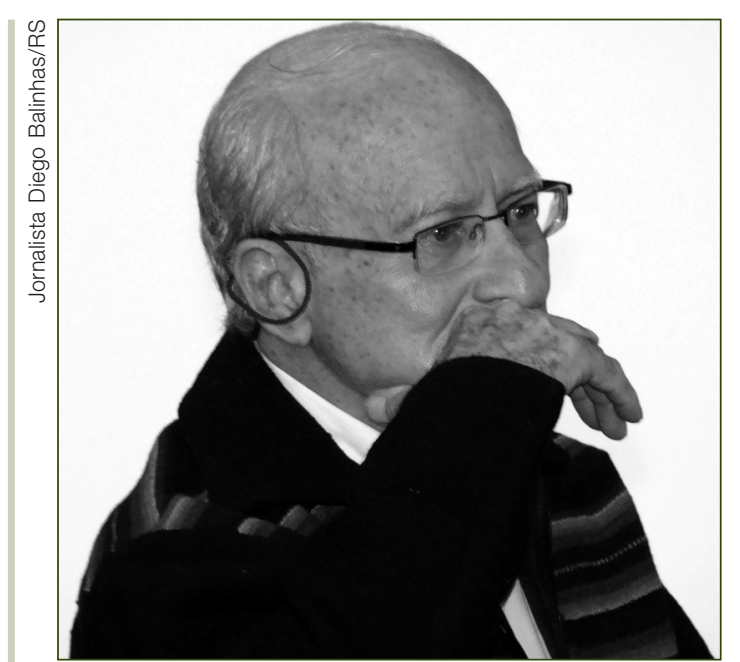

Juan Díaz Bordenave

Ivandro foi claro e preciso em seus conceitos. A participação implica dar poder às pessoas, disse. Ou melhor, que os diversos atores sociais aprendam a ter e exercer o poder. Consequentemente, a gestão democrática da sociedade consiste no cogoverno entre o Estado e a sociedade civil organizada.

Tradicionalmente, o Estado é visto como uma entidade, um todo separado da sociedade civil. Na realidade, para Ivandro, o Estado não é uma entidade mas uma função, que conjuga atribuições essenciais, tais como:

a) promover e coordenar os esforços da população para satisfazer suas necessidades básicas;

b) assegurar, pela força ou coerção, se necessário for, a ordem e a diversidade de interesses de indivíduos, grupos, categorias e classes sociais, frequentemente antagônicos entre si.

Até bem pouco tempo, cabia ao governo o monopólio da execução de tais atribuições. A gestão da sociedade era feita quase que exclusivamente por dirigentes e funcionários do aparato governamental (com frequência influenciados por grupos poderosos como as empresas multinacionais, as associações empresariais, e ate o crime organizado). Isto ocorria porque os diferentes grupos da sociedade não estavam suficientemente organizados nem capacitados, de modo que se supunha que a gestão de seus interesses deveria ser feita pelo governo. O Estado, leia-se o governo, era visto como responsável pelo bem comum.

Agora, o novo fenômeno que estamos vivendo, já há alguns anos, é que os setores não privilegiados da sociedade civil - movimentos camponeses, sindicatos, controladorias cidadãs e organizações de vizinhos, associações profissionais e de mulheres, e até igrejas - estão assumindo, conjuntamente com o Estado, o exercício das atribuições estatais. Além de trabalhar para satisfazer necessidades da população, muitas vezes melhor que o governo, as organizações estão fazendo elas próprias a gestão direta de seus interesses e desafiando aqueles governos que tentam continuar sendo gestores dos interesses da ordem capitalista.

Enfrentamos hoje a novidade histórica de que a sociedade civil se transforma em cogestora, com o governo, das políticas públicas, isto é, que assume, com o governo, a gestão dos diferentes interesses da sociedade. Temos que nos acostumar agora a pensar que as organizações da sociedade civil fazem parte do Estado, são seu braço civil. Não é possível mais falar em Estado e sociedade civil como entes separados. De agora em diante temos que falar em função estatal do governo e função estatal das organizações da sociedade civil. 
A contribuição dos meios públicos e alternativos • Juan Díaz Bordenave

Esta concepção é tão recente, tão nova que, quando os agentes do capital governam o governo, isto é, influenciam decisivamente sobre os aparatos governamentais do Estado, a sociedade civil não sabe ainda como desenvolver suas funções estatais e entregam seu destino a salvadores da pátria nas diversas instâncias do aparato governamental. E quando começa a querer colocá-las em prática, encontra a oposição do governo e das elites, o que obriga a sociedade civil a recorrer a meios anormais de intervenção como o bloqueio de estradas, ocupação de terras e outras medidas violentas, que seriam totalmente desnecessárias se a sociedade civil participasse de igual para igual nas decisões estatais.

No Brasil, o PT está promovendo sua própria versão da democracia participativa, a começar pelo orçamento participativo na cidade de Porto Alegre, há quinze anos. O sucesso desta modalidade de gestão democrática foi tão grande, que a maioria dos municípios brasileiros estão planejando colocá-la em prática. Ivandro, com seus alunos da Universidade Federal de Pernambuco, avaliou o estado atual do cogoverno no município de Camaragibe e concluiu que a prefeitura municipal ainda tem dificuldade em aceitar a participação dos representantes da sociedade civil, e estes últimos têm dificuldade em assumir o poder, acostumados que estão a ver o governo tomando as decisões importantes. Não obstante, ele informa que as plenárias, conferências e congressos, que são os órgãos que institucionalizam formalmente a cogestão, estão funcionando cada vez melhor.

\section{A CONTRIBUIÇÃO DA MÍDIA}

Estamos tão acostumados à onipresença e onipotência dos meios de comunicação comerciais que, para muitos, esta é a única forma de usar a comunicação na sociedade. Esquecem-se ou ignoram que, historicamente, a radiodifusão comercial é recente na maioria dos países ocidentais e que o normal eram os sistemas públicos de comunicação. Na maioria dos países europeus, a radiodifusão foi definida como um serviço público e, portanto, seu funcionamento ficou, a princípio, nas mãos do Estado.

Desse modo, criaram-se corporações públicas com a missão de planejar e explorar diretamente o serviço, produzindo programação de qualidade, acessível a toda a população, sem diferença alguma entre os habitantes das grandes cidades e os de localidades afastadas geograficamente.

Na década de 1920, foi criada no Reino Unido a BBC - British Broadcasting Corporation -, com o propósito de aproximar a maior quantidade de assuntos e de pessoas possível, tendo como finalidade educar, informar e entreter toda a nação, sem interferências políticas ou pressões comerciais.

\section{TIPOS DE RADIODIFUSÃO}

Para entender o papel da radiodifusão pública e da comunitária, é oportuno distinguir com clareza as semelhanças e diferenças que existem entre os diversos tipos de radiodifusão. Com efeito, coexistem em nossos países, Brasil e Paraguai, os seguintes tipos: 
1) Radiodifusão comercial

2) Radiodifusão estatal

3) Radiodifusão pública

4) Radiodifusão comunitária

5) Radiodifusão educativa

5) Radiodifusão internacional

1) A radiodifusão comercial é tradicionalmente concebida como um negócio de livre competição, orientado para o lucro e a acumulação de capital (e poder) por parte de empresários privados. Além de oferecer informação e entretenimento ao ouvinte ou espectador, ela serve de suporte ao marketing da produção industrial e de serviços.

2) A radiodifusão estatal, financiada e administrada pelo Estado, é concebida como um instrumento do governo para tornar públicas suas diretivas políticas e seus planos e projetos, bem como para divulgar suas realizações.

3) A radiodifusão pública, apesar de ser financiada pelo Estado, é independente do governo, isto é, não é administrada pelo próprio governo, e sim por algum tipo de corporação pública integrada por representantes da sociedade em geral.

4) A radiodifusão educativa, um ramo da radiodifusão pública, concentra-se na difusão de conteúdos da educação formal e não formal, para elevar o nível educativo da população. A Rádio Sutatenza, da Colômbia, foi a pioneira na América Latina e hoje a Asociación Latinoamericana de Educación Radiofónica (ALER) [Associação Latinoamericana de Educação Radiofônica] conta com diversas emissoras afiliadas em todo o continente.

5) A radiodifusão comunitária, como o nome indica, nasceu, segundo Brunetti, para "fortalecer a participação dos membros das comunidades, promovendo processos que facilitem e permitam obter objetivos específicos, destinados às reais necessidades"'.

6) A radiodifusão internacional compreende as transmissões que os países fazem como parte de sua influência geopolítica.

3. BRUNETTI, Vicente. Emergencia de las Radio Comunitaria en Paraguay. Litocolor: Asunción 1997.

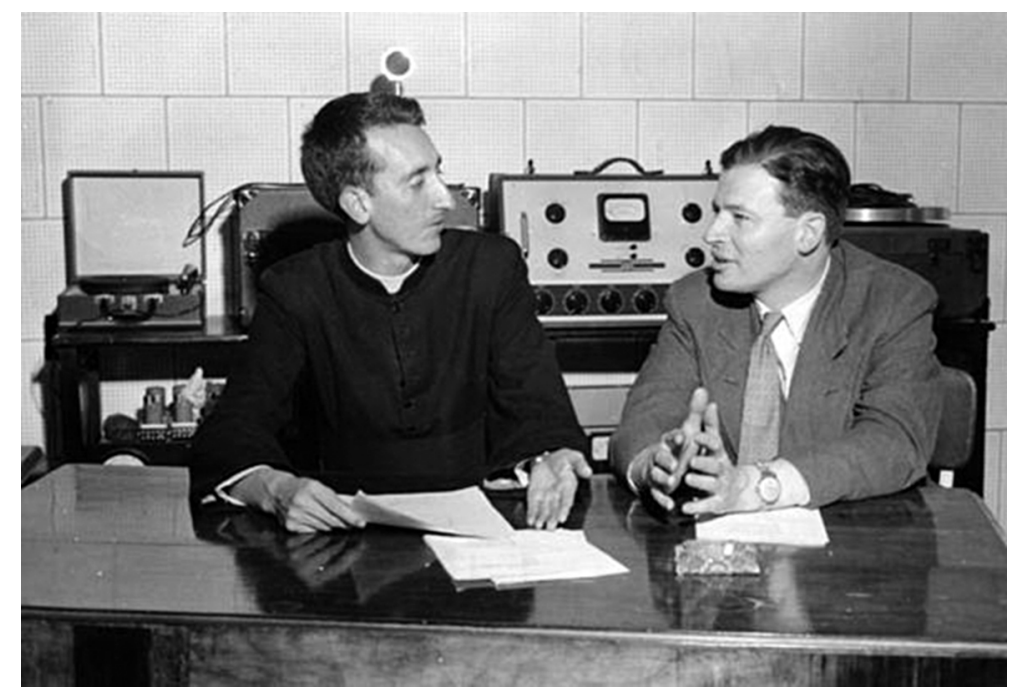

José Joaquín Salcedo, mais conhecido como Monseñor Salcedo, com Raymond Etchaes, da ONU, sobre o funcionamento da emissora. 


\section{A radiodifusão pública}

A premissa sobre a qual se fundamenta a radiodifusão pública é que as frequências através das quais se transmite a programação pertencem à comunidade e que, portanto, as mesmas devem ser utilizadas em seu exclusivo benefício. Com efeito, os cidadãos, a quem pertence o espectro de frequências, necessitam ter acesso a um meio capaz de oferecer-lhes informação confiável, tanto em relação aos temas de relevância pública quanto com outro tipo de questões ligadas a atividades culturais e de entretenimento.

No Brasil, em 1997, o deputado Jaques Wagner ${ }^{4}$ e outros do Partido dos Trabalhadores apresentaram ao congresso um projeto de lei para estabelecer o Sistema de Radiodifusão Pública no país. Os objetivos de tal sistema eram os seguintes:

1) permitir o exercício dos direitos à informação, à livre expressão do pensamento, à criação e à comunicação;

2) promover a cultura nacional, regional e local, e estimular a produção que tenha como objetivo sua divulgação;

3) promover a integração da sociedade civil, estimulando a recreação, a cultura e a convivência social;

4) prestar, permanentemente, serviços de utilidade pública, principalmente em situações de emergência e calamidade;

5) permitir a capacitação dos cidadãos no exercício do direito de expressão na forma mais acessível possível;

6) permitir o aperfeiçoamento profissional de pessoas que exerçam funções na área da comunicação.

A radiodifusão pública, para que possa ser pluralista, tanto política quanto culturalmente, não apenas deve ser absolutamente independente do Estado, exceto em seu financiamento, como também deve ser administrada por um diretório ou corpo colegiado formado por representantes dos diversos setores da sociedade civil, eleitos do modo mais democrático e transparente possível.

\section{A radiodifusão comunitária}

Para me referir à contribuição dos meios alternativos e, em particular, à dos comunitários, transcrevo a seguir as palavras de Tião Santos, fundador da primeira rádio comunitária do Brasil, a Rádio Novos Rumos, do município de Queimados, Rio de Janeiro, e ex-presidente da Federação Nacional que agrupa as emissoras desta natureza:

Os veículos comunitários e alternativos estabeleceram novos paradigmas na comunicação brasileira, seja em relação à criação de novos formatos e linguagens, seja na fantástica inversão da pirâmide, permitindo que aqueles que antes apenas escutavam, pudessem falar, interferindo diretamente na programação levada ao ar e, a partir de então, modificando de maneira significativa as relações sociais das comunidades em que estão operando ${ }^{5}$.

4. WAGNER, Jaques. Projeto de lei sobre Sistema de Radiodifusão Pública. Brasília, DF: Senado Nacional do Brasil, 1997.

5. I Congresso da Federação das Associações de Radiodifusão Comunitária do Rio de Janeiro, 2000. 
comunicação \& educação • Ano XVI • número 2 • jul/dez 2011

Hoje, cerca de 15 mil veículos alternativos estão no ar, a maioria ainda à espera de uma autorização formal. Apesar de a autorização formal ser bastante importante, o mais importante é o reconhecimento da população que, antes do reconhecimento estatal, já entende que estes veículos são legítimos e fundamentais para a vida comunitária e para o desenvolvimento local.

Olhando tudo o que ocorreu e está ocorrendo depois do advento das emissoras comunitárias, percebemos que está surgindo um novo modelo de comunicação. Uma comunicação mais colaborativa, capaz de modificar o meio local e, ao mesmo tempo, ter influência global. Uma comunicação de celebração, intimamente ligada à vida do entorno, suas lutas, dificuldades e esperanças, em que cada emissora torna-se o ponto de encontro das forças vivas da comunidade.

\section{O conceito de rádio comunitária}

Em minha participação no $1^{\circ}$ Congresso da Federação das Associações de Radiodifusão Comunitária do Rio de Janeiro, no ano 2000, defini minha percepção de que as rádios comunitárias, analisadas da perspectiva do desenvolvimento social humanista e sustentável, cumprem um papel fundamental no processo de fortalecimento da sociedade civil e da passagem da democracia meramente política para a democracia participativa, integralmente social.

Em tal processo, a rádio comunitária tem, entre outras, as seguintes funções:

1) facilita a comunicação representativa horizontal, isto é, o diálogo entre pessoas, grupos, instituições e comunidades, consentindo a participação e a cooperação;

2) mantém a população informada sobre seus direitos e obrigações, sobre as instituições de apoio e formas de obter serviços;

3) prestigia os valores básicos da democracia social e o desenvolvimento sustentável: anticonsumismo, equidade, cooperação, equilíbrio ecológico etc.;

4) educa e capacita a população, enriquecendo seu vocabulário, aumentando seu conhecimento, fortalecendo valores positivos, ensinando tecnologia, socializando métodos;

5) promove a identificação coletiva dos problemas da comunidade e sua articulação, seja para fins de resolvê-lo, seja para reivindicar soluções por parte do Estado e da sociedade;

6) catalisa a reflexão da comunidade sobre a realidade e seus problemas;

7) apoia a organização e a conscientização e facilita o aumento do poder da sociedade civil diante do Estado e do mercado;

8) Realimenta o povo sobre seu progresso na luta coletiva por uma vida melhor;

9) Celebra as vitórias das comunidades e da sociedade civil em geral.

No mesmo evento, concluí meu pensamento dizendo que esta lista nos diz que o importante no conceito de rádio comunitária são as funções que ela desempenha e não suas características de propriedade comunitária, baixa potência, pessoal voluntário e outras. 
A contribuição dos meios públicos e alternativos • Juan Díaz Bordenave

\section{PALAVRAS FINAIS}

Espero que esteja claro que a luta pela democratização da comunicação é a mesma luta pela democratização participativa. Com efeito, os cidadãos não poderiam participar da gestão democrática de sua sociedade se não tivessem os meios orgânicos para tal participação.

Acredito que as rádios e televisões públicas e comunitárias são um instrumento indispensável para a democracia participativa. Elas devem ter, por parte da legislação nacional, o reconhecimento pleno de sua função fundamental. Não vale a pena entrar em guerra contra as emissoras comerciais. Elas também cumprem sua função. Mas não podemos permitir que as emissoras comunitárias sejam tratadas como intrusas, de segunda classe, piratas e invasoras. Elas são as construtoras de nosso real e genuíno futuro democrático. O que temos que fazer, como sociedade, é capacitá-las e fiscalizar para que cumpram de forma cada vez melhor sua função social, sem se afastar jamais de sua missão e de seu caminho.

\section{REFERÊNCIAS BIBLIOGRÁFICAS}

BRUNETTI, Vicente. Emergencia de las Radio Comunitaria en Paraguay. Litocolor: Asunción, 1997.

SALES, Ivandro da Costa. Os desafios da gestão democrática da sociedade. Recife: Editora UFPES, 2008.

WAGNER, Jaques. Projeto de lei sobre Sistema de Radiodifusão Pública. Brasília, DF: Senado Nacional do Brasil, 1997. 


\section{BULLYING}

\section{cartas na mesa para aprender e prevenir}

Fenômeno mundial que atinge todas as classes e sexos, o bullying envolve uma série de questões arraigadas a comportamentos, culturas e formação ética e moral. Disposto a discutir o tema sem torná-lo um discurso moral, o filósofo e jornalista Silvio Costta oferece dicas para pais e educadores, entre elas a observação de seus praticantes e vítimas e 0 uso constante do diálogo.

A obra vem com um jogo de tabuleiro que tem como cenário as dependências de uma escola, onde ocorre a maior parte dos casos.

0 conceito do jogo cria situações que desenvolvem o ato da reflexão sem intimidar o jogador. Prático e divertido, viabiliza o mecanismo do diálogo, pois há uma função lógitoa para que as peças se movam. Isso faz com que ojogador, ao ler cada carta, desempenhe os principais papéis do fenômeno bullyiling (vítima, agressor e espectador), exercendo as trocas enquanto discute a questão.
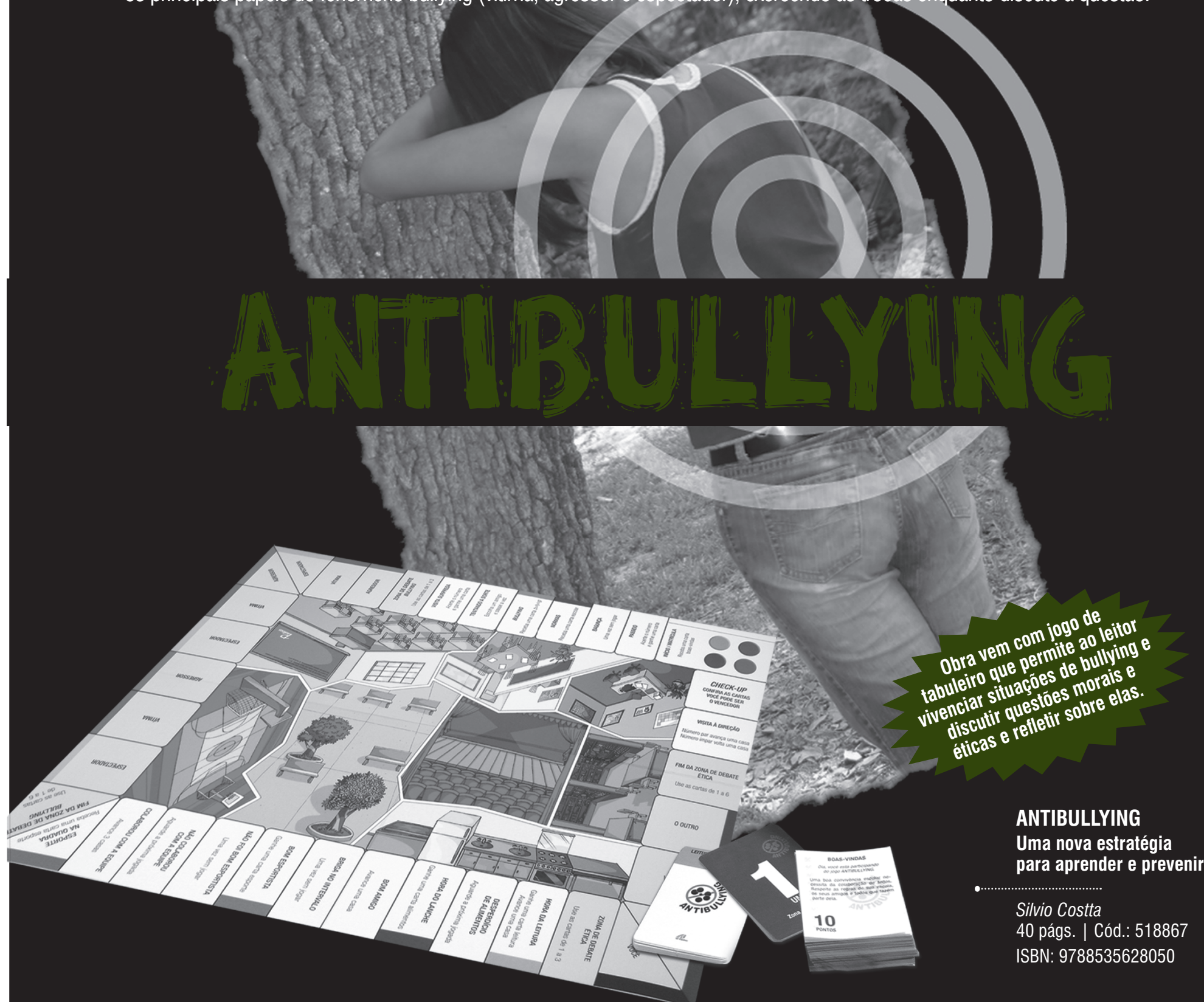

À venda na Rede Paulinas de Livrarias

Se preferir, ligue 08007010081 ou acesse www.paulinas.org.br/loja 